\title{
Neutron Radiography and Tomography: A New Approach to Visualize the Internal Structures of Pearls
}

\author{
Carina S. Hanser, Michael S. Krzemnicki, Christian Grünzweig, \\ Ralph P. Harti, Benedikt Betz and David Mannes
}

Non-destructive imaging of the internal structures of pearls has so far been mainly based on $\mathrm{X}$-ray imaging methods. As organic matter is almost transparent to X-rays, the identification of some structures can be difficult. This study shows that neutron imaging can be a helpful complementary method to visualize structures inside pearls beyond standard X-ray radiography and tomography, as neutrons are highly attenuated by hydrogen-bearing (organic) matter within pearls. The use of neutron radiography and tomography is shown for selected natural and cultured pearls (beaded and non-beaded). In addition, we present neutron phase contrast and darkfield images of a beaded cultured pearl, in analogy to X-ray phase contrast and darkfield imaging described in a previous study. While neutron imaging of pearls is particularly useful for understanding material inhomogeneities and void structures, this methodology is currently only available at large-scale facilities that are equipped to deal with nuclear reactions.

The Journal of Gemmology, 36(1), 2018, pp. 54-63, http://dx.doi.org/10.15506/JoG.2018.36.1.54

๑ 2018 The Gemmological Association of Great Britain

\section{INTRODUCTION}

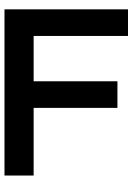

or about a century, the identification of pearls (i.e. differentiating between their natural or cultured formation; Figure 1) has been a crucial task for gemmologists, given the enormous differences in their rarity and price. Pearl identification is mostly based on the interpretation of internal structures, traditionally visualized by imaging methods such as X-ray radiography (Anderson, 1932; Scarratt et al., 2000; Strack, 2006; Sturman, 2009) and, more recently, X-ray computed microtomography (Wehrmeister et al., 2008; Karampelas et al., 2010; Krzemnicki et al., 2010; Otter et al., 2014) and X-ray phase contrast and darkfield imaging (Revol et al., 2016; Krzemnicki et al., 2017).

With this article, the authors present neutron imaging as a new and complementary method to visualize internal pearl structures. This paper is part of a larger joint research study between author $\mathrm{CSH}$, the SSEF Swiss Gemmological Institute and the Paul Scherrer Institute, in which a total of 32 samples (13 natural and 19 cultured pearls) were investigated with the aim of comparing various imaging methods for pearl testing (Hanser, 2015). It is a follow-up to the article about X-ray phase contrast and darkfield imaging that was recently published in The Journal (Krzemnicki et al., 2017).

Similar to X-rays, neutrons can be applied for imaging purposes because of their selective attenuation via absorption and scattering by certain materials. But unlike X-rays, neutrons interact with the atomic nuclei only. Thus, even some lighter elements such as hydrogen strongly attenuate neutrons, whereas X-rays (which interact with the electrons of atoms) are very weakly attenuated by light elements and are increasingly affected by heavier elements (directly related to the element's atomic number). Generally speaking, neutron radiography images are inverse to 
$\mathrm{X}$-ray radiographs in many aspects, and in the case of pearls can reveal complementary information to the gemmologist. Calcium carbonate, which forms the pearl, absorbs neutrons rather weakly (and thus appears dark grey in neutron radiographs) in contrast to X-rays, which are strongly absorbed (appearing bright grey in X-ray radiographs). In contrast to this, zones rich in organic matter (and hydrogen) appear bright grey in neutron radiographs (i.e. they are strongly attenuated), whereas they are dark grey in X-ray radiographs (weakly attenuated). Empty cavities, drill holes and fissures remain dark in both methods, as both neutrons and X-rays are well transmitted and not absorbed.

The fact that neutrons are strongly attenuated by some lighter elements such as hydrogen makes them particularly interesting for imaging purposes in which organic matter is involved, such as in materials science (Lehmann and Wagner, 2010; Kardjilov et al., 2011), archaeology and cultural heritage studies (Lehmann et al., 2005; Mannes et al., 2015), including historic jewellery (Rehren et al., 2013; Saprykina et al., 2017), gemstones and pearls (Okamoto et al., 1983; Vontobel and Lehmann,
2010; Hanser, 2015; Mannes et al., 2017; Vitucci et al., 2018).

Pearls commonly contain macroscopic organic matter and void/cavity/fissure features within their calcium-carbonate matrix. As calcium, carbon and oxygen do not interact strongly with neutrons, high contrast between the hydrogen-containing organic matter and the calcium-carbonate polymorphs in pearls can be achieved with neutron imaging methods, as shown in this article.

\section{MATERIALS AND METHODS}

For this article we selected two natural and four cultured pearls (see Table I) from the 32 previously investigated samples in order to represent the full range of types (freshwater and saltwater, natural as well as beaded and non-beaded cultured) and display the most telling internal features. All of them had been identified and fully characterized using X-ray radiography and tomography, X-ray phase contrast and darkfield imaging, and energy-dispersive X-ray fluorescence spectroscopy for assessing freshwater vs. saltwater origin.

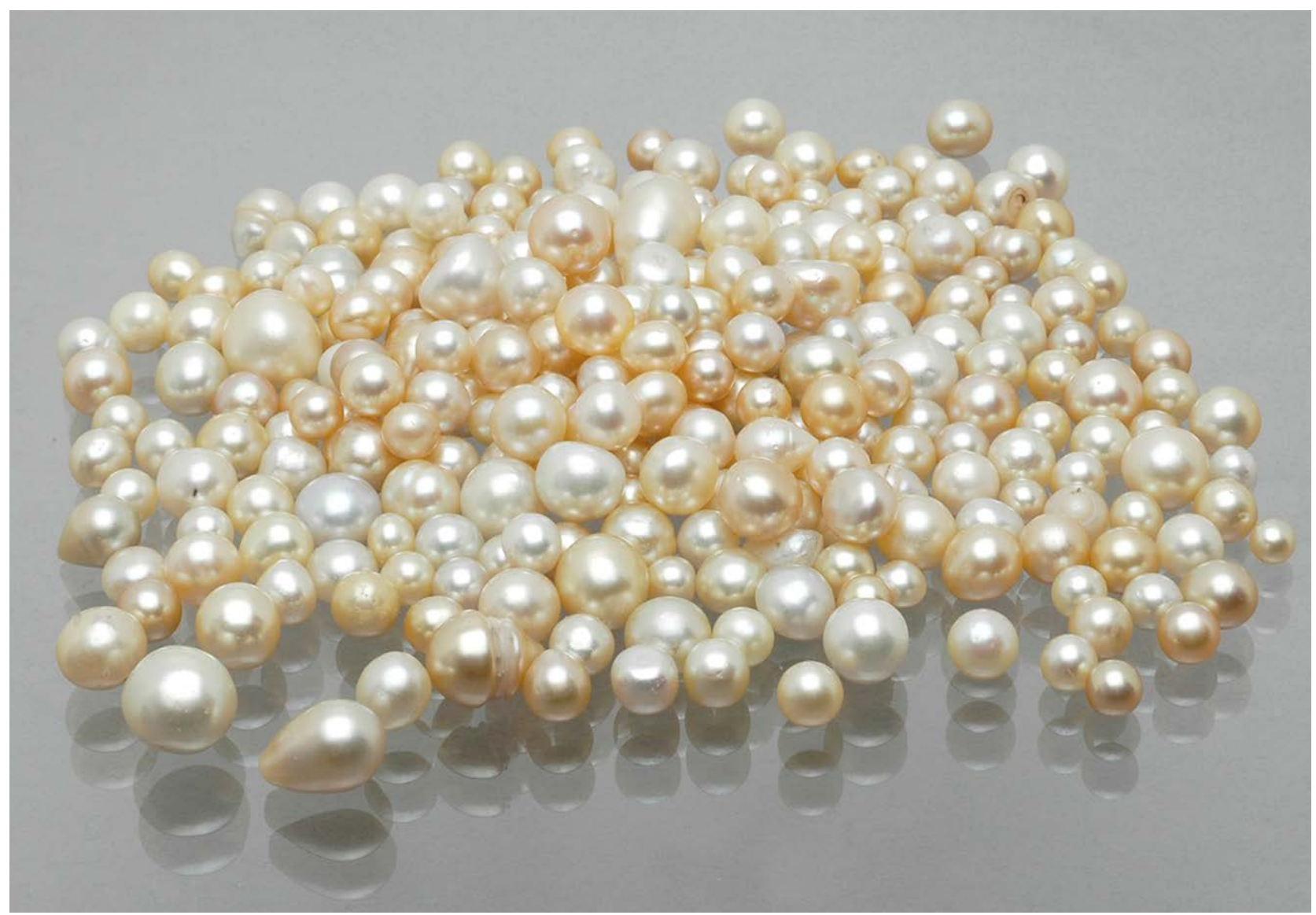

Figure 1: These pearls (0.7-9.3 ct) were submitted to SSEF for identification and differentiation into natural or cultured origin. Neutron imaging can complement the use of X-rays for difficult cases of identification that might be encountered in a group of pearls such as this. Photo by Luc Phan, (c) SSEF. 
Table I: Natural and cultured pearls analysed for this study.

\begin{tabular}{|c|c|c|c|c|c|c|c|}
\hline Sample no. & Type & $\begin{array}{c}\text { Bead } \\
\text { Nucleus }\end{array}$ & Origin & Species & Source & $\begin{array}{c}\text { Weight } \\
(\mathbf{c t})\end{array}$ & $\begin{array}{c}\text { Diameter } \\
(\mathbf{m})\end{array}$ \\
\hline NP-2e & Natural & - & Saltwater & $\begin{array}{c}\text { Pinctada } \\
\text { radiata }\end{array}$ & Bahrain & 6.49 & 10.3 \\
\hline NP-2i & Natural & - & Saltwater & $\begin{array}{c}\text { Strombus } \\
\text { gigas }\end{array}$ & $\begin{array}{c}\text { Caribbean } \\
\text { Sea }\end{array}$ & 1.86 & 7.3 \\
\hline CP-1b & Cultured & Non-beaded & Freshwater & $\begin{array}{c}\text { Hyriopsis } \\
\text { cumingii }\end{array}$ & China & 9.92 & 13.0 \\
\hline CP-2m & Cultured & Non-beaded & Saltwater & $\begin{array}{c}\text { Pinctada } \\
\text { margaritifera }\end{array}$ & Polynesia & 8.14 & 13.8 \\
\hline CP-2a & Cultured & Beaded & Saltwater & $\begin{array}{c}\text { Pinctada } \\
\text { fucata }\end{array}$ & Asia & 3.89 & 8.3 \\
\hline CP-2g & Cultured & Beaded & Saltwater & $\begin{array}{c}\text { Pinctada } \\
\text { margaritifera }\end{array}$ & Polynesia & 12.14 & 16.6 \\
\hline
\end{tabular}

Neutron imaging was performed using the ICON beamline (Kaestner et al., 2011) of the Paul Scherrer Institute (PSI) in Villigen, Switzerland (Figure 2), using a cold neutron spectrum. Since neutrons (i.e. the uncharged particles of an atom's core) can be generated only by nuclear reactions, obtaining access to neutrons is limited to large-scale facilities. The two nuclear reactions that are commonly applied for this purpose are fission and spallation (see Glossary). At PSI, the neutrons were generated with a SINQ continuous spallation source (Blau et al., 2009), and were then passed into a moderator tank filled with heavy water at ambient conditions (to produce a thermal neutron spectrum) and a cold moderator filled with liquid deuterium at $25 \mathrm{~K}$ (for a cold neutron spectrum).
For neutron radiography, the pearls were placed on a sample holder using double-sided tape and affixed to an aluminium bar. To keep them in position, some of the pearls were wrapped in aluminium foil, as aluminium is practically transparent to neutrons. For neutron tomography, the samples were wrapped in aluminium foil and placed inside a thin-walled aluminium cylinder, which was placed close to the detector. The acquisition time was $90 \mathrm{~s}$ for each radiograph, recorded with a proton current of $1.42 \mathrm{~mA}$ by a scintillator-CCD camera system with a field of view of $27 \times$ $27 \mathrm{~mm}(2048 \times 2048$ pixels $)$ and a corresponding pixel size of $13.5 \mu \mathrm{m} /$ pixel (Lehmann et al., 2007). The scintillator was a gadolinium oxysulfide screen with a coating thickness of $20 \mu \mathrm{m}$. For neutron
Figure 2: Shown here is a portion of the ICON beamline at the Paul Scherrer Institute that provides a cold neutron spectrum. The neutron beam passes through the exit and the field of vision and then strikes the sample. The signal produced is then recorded by a scintillator-CCD camera system (not visible in this image). Photo by C. Hanser.

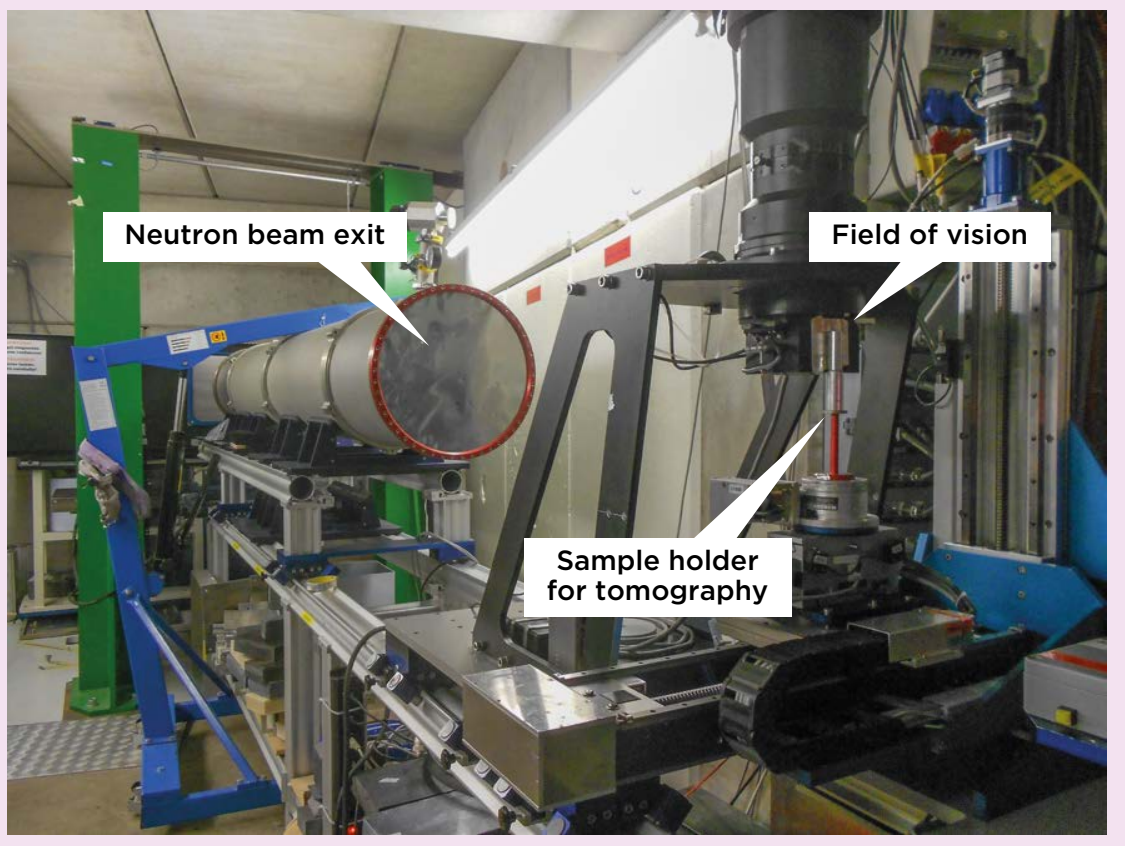




\section{Glossary}

Nuclear fission: Highly energetic radioactive decay process by which an atomic core (nucleus) is split into smaller/lighter nuclei (e.g. in a chain reaction), often accompanied by the production of free neutrons and gamma radiation.

Nuclear spallation: Using a particle accelerator, a heavy nucleus (atom) emits a large number of neutrons each time it is hit by a high-energy particle. These highly energetic neutrons have to be slowed down to be usable for analysis purposes by a process known as moderation.

tomography the same setup was used, with each tomograph consisting of 626 radiographs over $360^{\circ}$, summing up to an overall acquisition time of approximately 22 hours.

None of the analysed pearls showed any change in colour after exposure to the neutrons. However, they did become temporarily radioactive due to the long time necessary for neutron tomography, and had to remain at the facility until reaching a threshold level below $0.1 \mu \mathrm{Sv} / \mathrm{h}$ (as tested by a radiation protection officer using an officially calibrated dosimeter), a process which took several hours to a few days for the various pearls.

Neutron phase contrast and darkfield imaging were performed with the samples fixed on doublesided tape and using a lower acquisition time of $45 \mathrm{~s}$ for each image. No residual radioactivity was detected in the samples after this type of imaging. A detailed description of the setup and neutron interferometer gratings is given by Grünzweig et al. (2008) and Mannes et al. (2017).

\section{RESULTS AND DISCUSSION}

X-ray and neutron imaging were done independently on two completely different instrumental setups, and although we attempted to fix the samples in a consistent orientation, we were unable to obtain images with a perfectly matching sample position. All radiographs were edited (contrast sharpening and homogenizing of the black background around the samples) using built-in filters in Adobe Photoshop software. A comparison of X-ray radiography and neutron radiography images immediately reveals the complementary nature of these two methods.

\section{Examples of Natural Pearls}

Figure 3 shows natural pearl sample NP-2e (Pinctada radiata), which is characterized by an organic-rich core of radially arranged calcite prisms and multiple radial fissures overgrown by a nacre layer about $3 \mathrm{~mm}$ thick with weak onion-like structures. In the X-ray radiograph (Figure $3 \mathrm{~b}$ ) the nacre is distinctly brighter (higher X-ray attenuation) compared to the organic-enriched core (lower X-ray attenuation). Fissures appear dark, as they are voids with no attenuation effect on X-rays. (Note: Readers wishing to see X-ray phase contrast and darkfield images of this pearl are directed to Figure 6 in Krzemnicki et al., 2017.)

Neutron radiography of this pearl (Figure 3c) shows the inverse to X-radiography, with a brighter core owing to the enrichment of organic matter (i.e. strong neutron attenuation by hydrogen) compared to the dark grey nacre (distinctly lower neutron attenuation by calcium carbonate). Similar to the X-ray radiograph, the void fissures (mainly visible in the core) are dark, indicating no neutron attenuation; it can therefore be postulated that they contain no organic matter. However, compared to the image
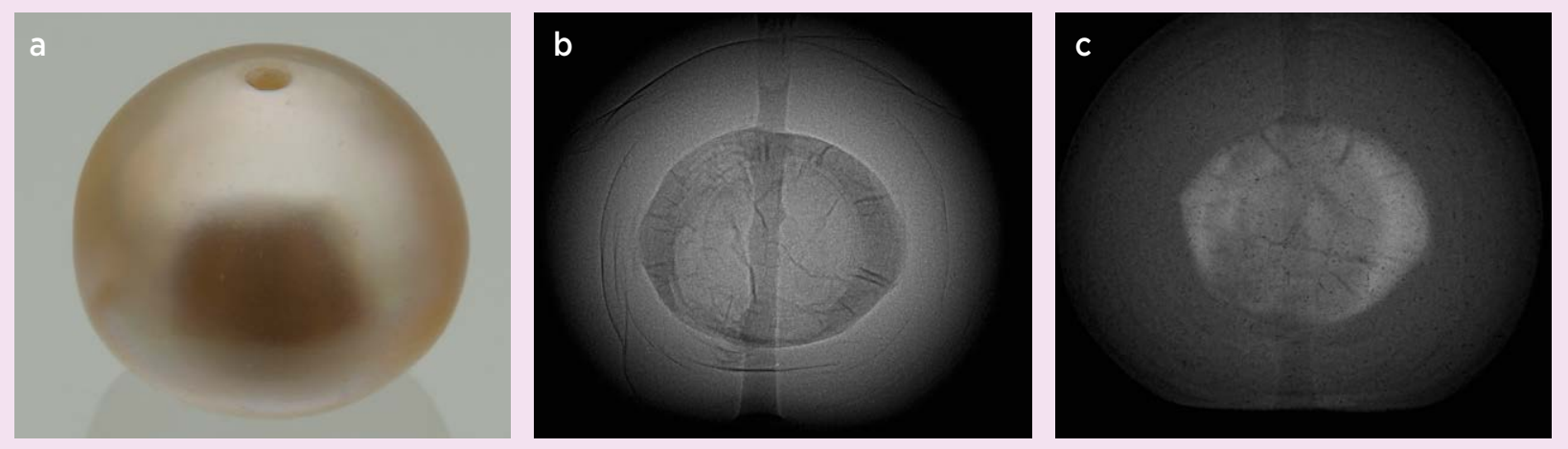

Figure 3: (a) Saltwater natural pearl NP-2e (Pinctada radiata, $10.3 \mathrm{~mm}$ in diameter) is shown here with its $\mathrm{X}$-ray radiograph (b) and neutron radiograph (c). The inverse attenuation of the organic-rich core (dark grey in $X$-rays and light grey in neutrons) and the dense surrounding nacre layer (light grey in $\mathrm{X}$-rays and dark grey in neutrons) is obvious. 


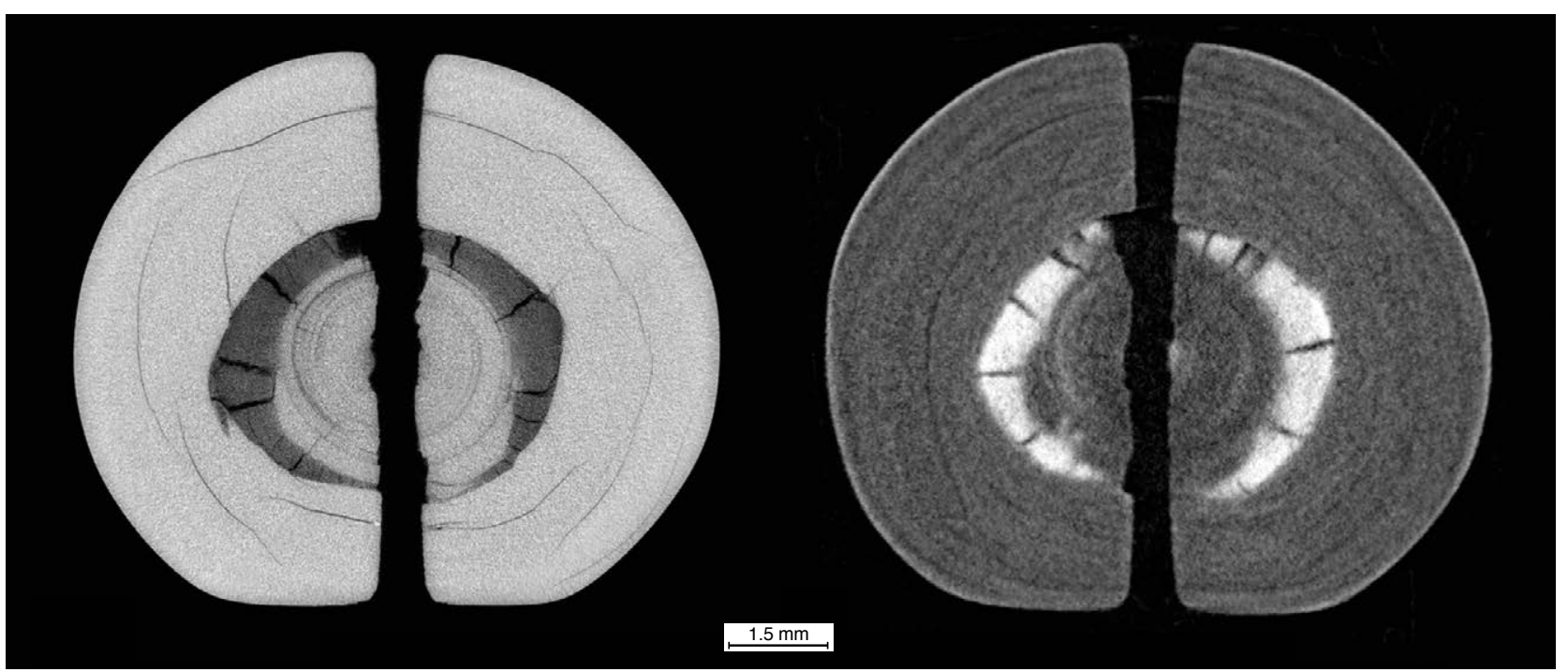

Figure 4: X-ray tomography (left) and neutron tomography (right) of the natural pearl shown in Figure 3 also illustrates the inverse attenuation of $X$-rays and neutrons in pearls. The organic-rich outer core layer with numerous radiating desiccation fissures appears dark grey in X-rays and bright grey in neutrons.

obtained with state-of-the-art digital X-ray radiography, the neutron radiograph appears less sharp using the current analytical setup.

Better contrast and resolution are shown by image slices of the same sample obtained by X-ray and neutron tomography (Figure 4). These images reveal that this saltwater natural pearl in fact contains an irregularly shaped core consisting of two phases: (1) an inner core portion dominated by calcium carbonate that appears bright grey in the X-ray tomograph and dark grey in the neutron tomograph (and also contains tiny radial calcite columns, of the type pictured in Figure 3b of Gutmannsbauer and Hänni [1994], together with fine onion-like structures), and (2) an outer core layer of calcium carbonate that is heavily enriched in organic matter and appears dark grey in the X-ray tomograph and bright grey in the neutron tomograph (along with pronounced desiccation fissures). The reason for such a distinct enrichment of organic matter in the outer core is not known, but might be the result of a haemorrhage event within the pearl sac during formation of this natural pearl. These tomographic slices allow a much more detailed interpretation of internal structures because they are not blurred by condensing a three-dimensional pearl on to a two-dimensional image, as with radiography.

Figure 5 shows a comparison of image slices obtained by X-ray and neutron tomography of non-nacreous natural pearl sample NP-2i, reportedly from Strombus gigas (Sue Hendrickson, pers. comm., 2015). This pearl is characterized by a large irregular-shaped internal cavity that is partially filled with numerous small spherules. X-ray tomography
(Figure 5b) shows a rather strong attenuation of these spherules, resembling the bright appearance of the non-nacreous calcium carbonate surface layer (densely interwoven fibrous aragonite), thus indicating a rather calcareous nature of these spherules. However, the neutron tomograph (Figure 5c) clearly illustrates that these spherules also highly attenuate neutrons and are thus presumably rich in hydrogen. This indicates a distinctly different nature than the calcium carbonate (aragonite) of the pearl's surface. Similar tiny spherules have been documented previously (see Figure 4 in Krzemnicki et al., 2010), and research into their nature is ongoing.

\section{Examples of Cultured Pearls}

Figure 6 shows non-beaded freshwater cultured pearl $\mathrm{CP}-1 \mathrm{~b}$ (Hyriopsis cumingii), imaged using X-ray and neutron radiography. Both images are dominated by a rather uniform attenuation as a result of the dense nacre of this cultured pearl. The irregular 'moustache' structure in the centre is clearly visible in the X-ray radiograph but also to some extent in the neutron image. (The slightly different shape of this structure in these two radiographs is due to variations in the sample's orientation.) Such tiny structures are highly characteristic of mantle-grown non-beaded cultured pearls (Scarratt et al., 2000; Strack, 2006). The fact that this structure is dark grey (i.e. has very low attenuation) in both types of radiographs indicates that it actually represents a tiny folded void and-at least in this case-is not filled with organic matter. The X-ray radiograph (Figure 6b) also shows a few very fine dark ring structures, which appear light grey in the neutron radiograph (Figure 6c), thus 
a

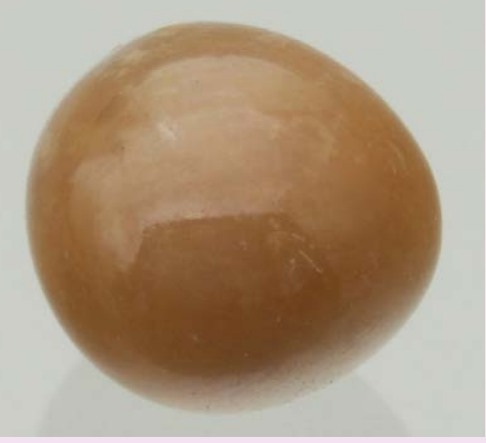

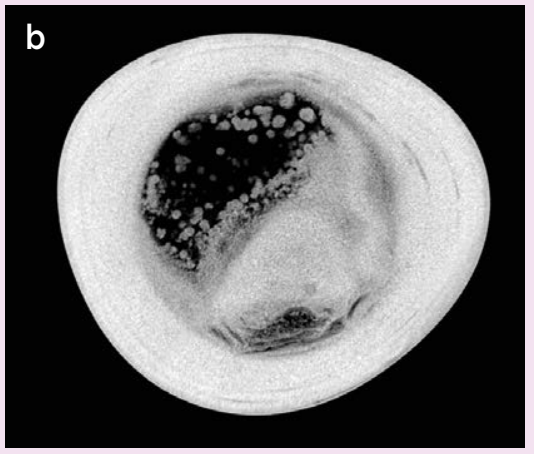

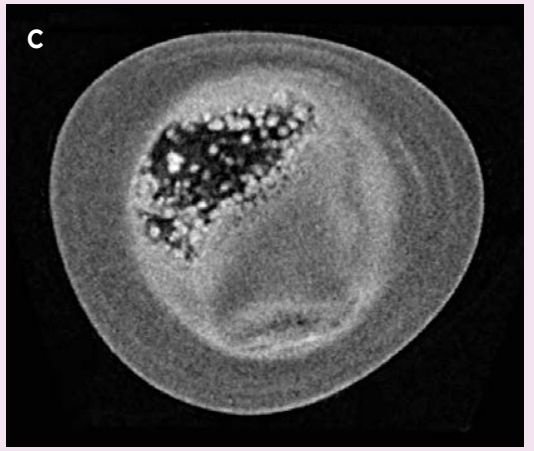

Figure 5: (a) Non-nacreous natural pearl NP-2i (Strombus gigas, $7.3 \mathrm{~mm}$ in diameter) is shown with its corresponding tomographic slices obtained using X-rays (b) and neutrons (c), which reveal a large cavity containing numerous small spherules.

implying that they represent onion-like growth features enriched in organic matter. However, the fuzzy appearance of the neutron radiograph obtained with the current analytical setup demonstrates that it is not the first choice for visualizing such fine internal features crucial for pearl identification. Much more detailed X-ray phase contrast and darkfield images of this same cultured pearl are presented in Figure 9 of Krzemnicki et al. (2017).

Figure 7 shows the complex external and internal structures of non-beaded saltwater cultured pearl CP-2m (Pinctada margaritifera; see also Figure 10 in Krzemnicki et al., 2017). The neutron radiograph (Figure 7b) highlights local concentrations of organic matter (containing hydrogen) as bright areas. The baroque shape, however, creates spurious overlay effects when condensed into a two-dimensional $\mathrm{X}$-ray radiograph (which is therefore not shown here for comparison). As evident in the reconstructed image slices obtained by X-ray and neutron tomography (Figures $7 \mathrm{c}$ and $7 \mathrm{~d}$ ), the internal structures are much more discernible and displayed in great detail by both methods. The main feature is a large folded cavity structure (dark grey to black in the X-ray tomograph), accentuated by desiccation fissures. The neutron tomograph provides additional information that is different from what can be inferred from the X-ray tomography only. What seems to be an open void on the left side of the large folded cavity structure in the X-ray image proves to be filled with organic matter (bright grey in the neutron tomograph). The remaining part of the folded cavity is only coated by a thin layer of organic material resulting in a fine but pronounced light grey depiction of the cavity's outline. The smaller additional cultured pearl attached at the top, also known by the Japanese term tokki, is a common feature for gonad-grown cultured pearls (Krzemnicki et al., 2011; Gauthier et al., 2015). Interestingly, this tokki shows a small dark ring (with a tiny brighter spot in its centre) in both tomographic images. Based on X-ray tomography, this feature could be misinterpreted as having a local enrichment of organic matter in a small growth ring. The low neutron a

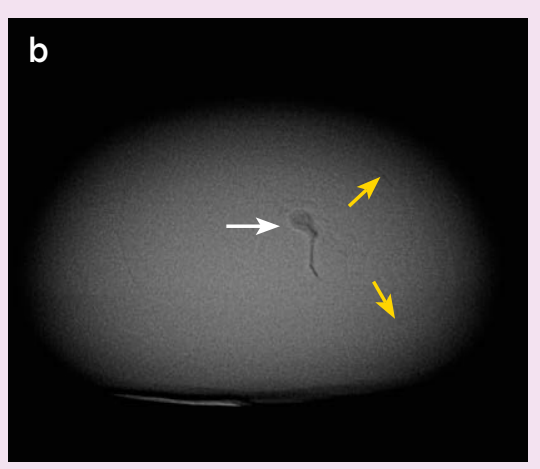

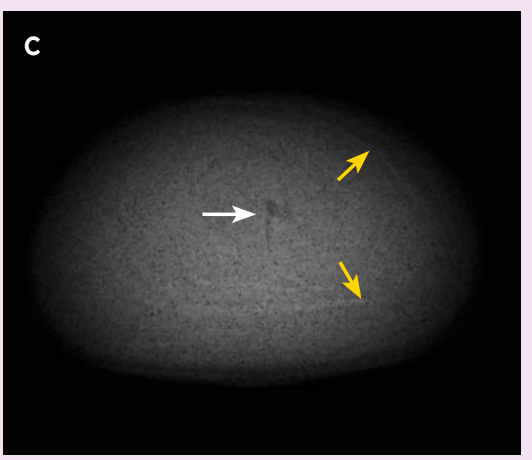

Figure 6: (a) Non-beaded freshwater cultured pearl CP-1b (Hyriopsis cumingii, $13.0 \mathrm{~mm}$ in diameter) is shown with its $\mathrm{X}$-ray (b) and neutron (c) radiographs. The latter two images were not taken in exactly the same position, resulting in a slightly different appearance of the tiny 'moustache' void structure in the centre (white arrows). Fine growth rings (yellow arrows) appear light grey in the neutron radiograph, indicating that they are enriched in organic matter. 
Figure 7: (a) Non-beaded saltwater cultured pearl CP-2m (Pinctada margaritifera, $13.8 \mathrm{~mm}$

in diameter) is imaged with neutron radiography (b)

X-ray tomography (c) and neutron tomography (d).

The tomographic sections display a large folded cavity structure (yellow arrows), with distinct enrichment of organic matter shown in the neutron tomograph. Attached to the top of the sample is a smal additional cultured pearl (tokki), with a dark growth ring marked by white arrows.
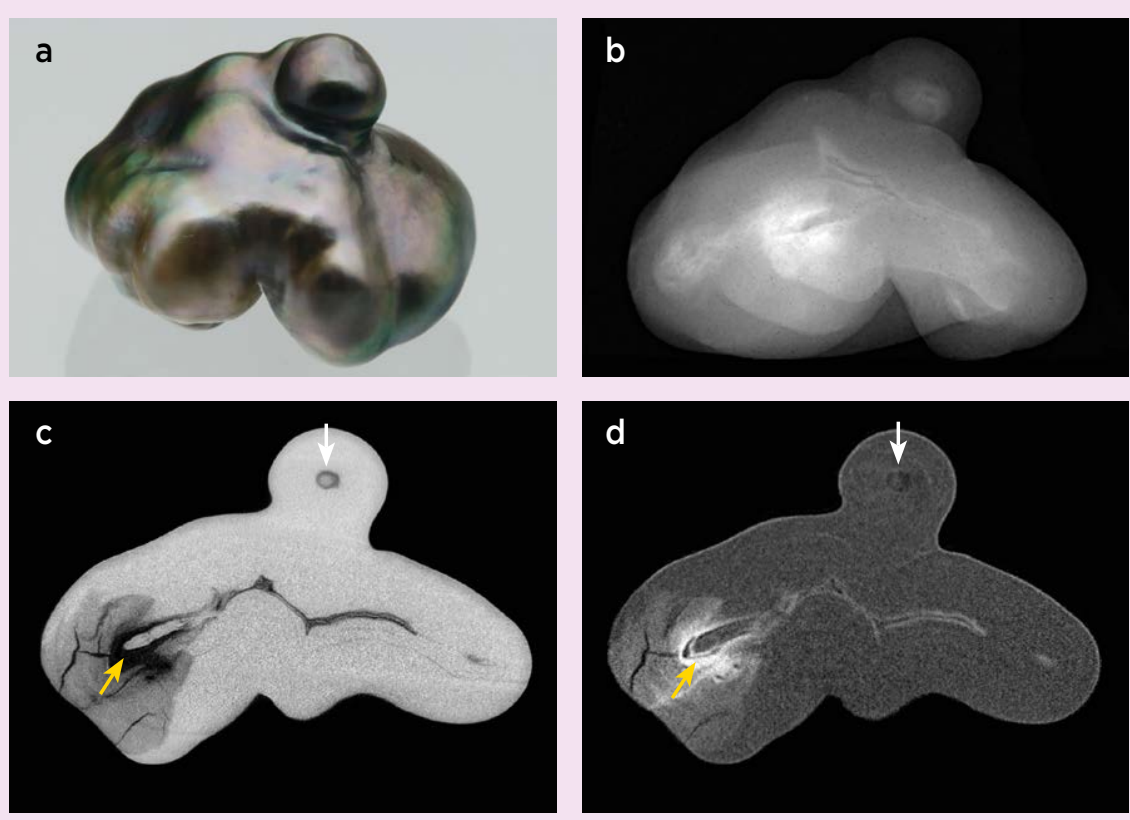
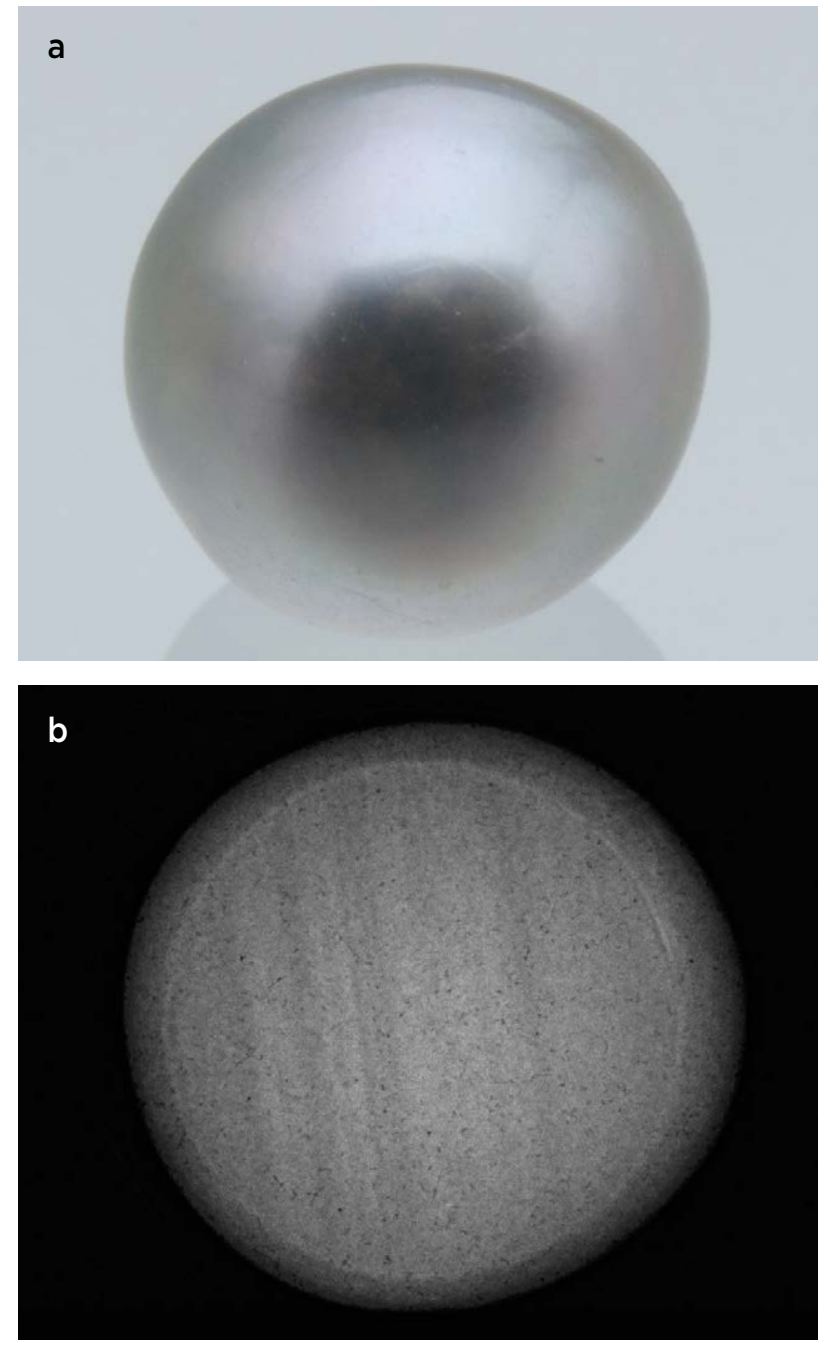

Figure 8: (a) Imaging of Akoya-type beaded saltwater cultured pearl CP-2a (Pinctada fucata, $8.3 \mathrm{~mm}$ in diameter) was performed with neutron radiography (b), which reveals a banded structure within the shell bead and a thin light grey circle resulting from a film of organic matter on the bead. attenuation by this feature, however, indicates that the growth ring might be due to another reason, such as a distinctly lower nacre density.

Beaded cultured pearls are readily identified with both X-ray and neutron radiography. Figure 8 shows Akoya-type beaded cultured pearl CP-2a (Pinctada fucata) with distinct banding in the shell bead (a freshwater origin for this bead was confirmed by X-ray luminescence imaging; see Hänni et al., 2005). Inversely to X-ray radiography, the darker bands in the neutron radiograph are not inferred to represent layers showing variations in organic matter but rather zones of denser freshwater shell material, whereas the brighter bands might contain slightly higher amounts of organic matter. (An X-ray radiograph of this sample is not included here for comparison because it was taken in a slightly different position and therefore did not show the internal layering of the bead.) The bright thin layer between bead and nacre overgrowth represents a thin film of organic matter deposited on the bead in the newly formed pearl sac before the nacre overgrowth formed during pearl cultivation. The bead appears slightly brighter than the surrounding nacre because, as with all spherical objects, there is a gradual increase of attenuation with increasing transmission path through the sample. In addition, the thin layer of organic matter (seen here as the light grey circle between the bead and nacre overgrowth) also might contribute to the brighter overall appearance of the bead in this neutron radiograph.

A final example (Figure 9) is provided by beaded saltwater cultured pearl CP-2g (Pinctada 


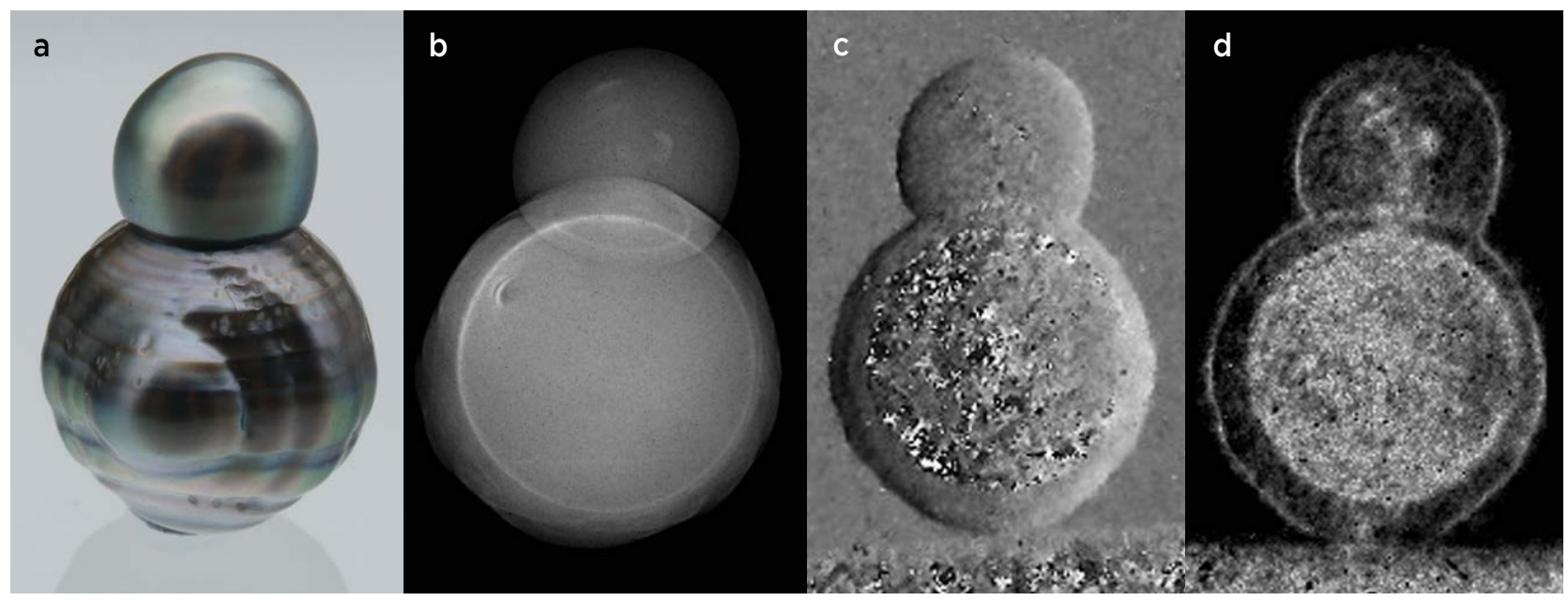

Figure 9: (a) Saltwater cultured pearl CP-2g (Pinctada margaritifera, $16.6 \mathrm{~mm}$ in diameter) is shown with its neutron radiograph (b), neutron phase contrast image (c) and neutron darkfield image (d). The bead is readily discernible by its organic coating, both with neutron radiography (bright grey circle) and neutron interferometry, which shows different appearances related to artefacts (in the neutron phase contrast image) and small-angle scattering (in the darkfield image).

margaritifera) with a relatively large additional cultured pearl (tokki) and distinct circling structures in two directions on its surface (cf. Gauthier et al., 2015). The bead is easily recognized in the neutron radiograph (Figure 9b) by a bright grey outline resulting from a distinct organic layer that surrounds it. For this sample (and all other samples studied by Hanser, 2015), we present additional neutron phase contrast and neutron darkfield images (Figures 9c and $9 \mathrm{~d}$, respectively). Using the current setup and analytical parameters, these images are, however, characterized by rather low resolution and noticeable artefacts, which limits their usefulness. The neutron phase contrast image reveals a noisy signal related to the bead, whereas in the neutron darkfield image the organic-rich coating on the bead and a few organicrich spots in the tokki produce strong neutron smallangle scattering (i.e. a distinct bright reaction).

\section{CONCLUSIONS}

Most structures inside pearls can be visualized readily by X-ray imaging methods. However, neutron radiography and tomography can yield additional information that cannot be obtained by X-rays. Neutron imaging methods are especially useful to better understand material inhomogeneities and void structures, as well as filling substances (solid or liquid) in large hollow pearls (cf. Otter et al., 2014). Since access to neutron imaging techniques is, however, limited to large-scale facilities, their routine application to gemmological testing is impossible at this time. Still, in difficult cases of identifying the nature of a pearl, further analysis with neutrons can be helpful. It is important to note that activation of the samples as a result of neutron tomographic imaging will likely require that they be quarantined for up to several days after testing.

\section{REFERENCES}

Anderson B.W., 1932. The use of X rays in the study of pearls. British Journal of Radiology, 5(49), 57-64, http://dx.doi.org/10.1259/0007-1285-5-49-57.

Blau B., Clausen K.N., Gvasaliya S., Janoschek M., Janssen S., Keller L., Roessli B., Schefer J., Tregenna-Piggott P., Wagner W. and Zaharko O., 2009. The Swiss spallation neutron source SINQ at Paul Scherrer Institut. Neutron News, 20(3), 5-8, http://dx.doi.org/10.1080/10448630903120387.

Gauthier J.-P., Gutierrez G., Serrar M. and Bui T.N., 2015. Rares perles cerclées à double axe de rotation [Rare circled pearls with a double axis of rotation]. Revue de Gemmologie A.F.G., No. 194, 4-7 (in French).

Grünzweig C., Pfeiffer F., Bunk O., Donath T., Kühne G., Frei G., Dierolf M. and David C., 2008. Design, fabrication, and characterization of diffraction gratings for neutron phase contrast imaging. Review of Scientific Instruments, 79(5), article 053703, 6 pp., http://dx.doi.org/10.1063/1.2930866.

Gutmannsbauer W. and Hänni H.A., 1994. Structural and chemical investigations on shells and pearls of nacre forming salt- and freshwater bivalve molluscs. Journal of Gemmology, 24(4), 241-252, http://dx.doi.org/10.15506/jog.1994.24.4.241. 
Hänni H.A., Kiefert L. and Giese P., 2005. X-ray luminescence, a valuable test in pearl identification. Journal of Gemmology, 29(5-6), 325-329, http:// dx.doi.org/10.15506/JoG.2005.29.5.325.

Hanser C., 2015. Comparison of Imaging Techniques for the Analysis of Internal Structures of Pearls. Master's thesis, University of Freiburg, Germany, 137 pp.

Kaestner A.P., Hartmann S., Kühne G., Frei G., Grünzweig C., Josic L., Schmid F. and Lehmann E.H., 2011. The ICON beamline - A facility for cold neutron imaging at SINQ. Nuclear Instruments and Methods in Physics Research Section A: Accelerators, Spectrometers, Detectors and Associated Equipment, 659(1), 387-393, http://dx.doi.org/10.1016/j. nima.2011.08.022.

Karampelas S., Michel J., Zheng-Cui M., Schwarz J.-O., Enzmann F., Fritsch E., Leu L. and Krzemnicki M.S., 2010. X-ray computed microtomography applied to pearls: Methodology, advantages, and limitations. Gems \& Gemology, 46(2), 122-127, http://dx.doi.org/10.5741/gems.46.2.122.

Kardjilov N., Manke I., Hilger A., Strobl M. and Banhart J., 2011. Neutron imaging in materials science. Materials Today, 14(6), 248-256, http://dx.doi. org/10.1016/s1369-7021(11)70139-0.

Krzemnicki M.S., Friess S.D., Chalus P., Hänni H.A. and Karampelas S., 2010. X-ray computed microtomography: Distinguishing natural pearls from beaded and non-beaded cultured pearls. Gems \& Gemology, 46(2), 128-134, http://dx.doi. org/10.5741/gems.46.2.128.

Krzemnicki M.S., Mueller A., Hänni H.A., Gut H.-P. and Düggelin M., 2011. Tokki pearls: Additional cultured pearls formed during pearl cultivation: External and internal structures. 32nd International Gemmological Conference, Interlaken, Switzerland, 13-17 July, 56-58.

Krzemnicki M.S., Hanser C.S. and Revol V., 2017. Simultaneous X-radiography, phase contrast and darkfield imaging to separate natural from cultured pearls. Journal of Gemmology, 35(7), 628-638, http://dx.doi.org/10.15506/JoG.2017.35.7.628.

Lehmann E.H. and Wagner W., 2010. Neutron imaging at PSI: A promising tool in materials science and technology. Applied Physics A, 99(3), 627-634, http://dx.doi.org/10.1007/s00339-010-5606-3.

Lehmann E.H., Vontobel P., Deschler-Erb E. and Soares M., 2005. Non-invasive studies of objects from cultural heritage. Nuclear Instruments and Methods in Physics Research Section A: Accelerators, Spectrometers, Detectors and Associated Equipment, 542(1-3), 68-75, http://dx.doi.org/10.1016/j. nima.2005.01.013.
Lehmann E.H., Frei G., Kühne G. and Boillat P., 2007. The micro-setup for neutron imaging: A major step forward to improve the spatial resolution. Nuclear Instruments and Methods in Physics Research Section A: Accelerators, Spectrometers, Detectors and Associated Equipment, 576(2-3), 389-396, http:// dx.doi.org/10.1016/j.nima.2007.03.017.

Mannes D., Schmid F., Frey J., Schmidt-Ott K. and Lehmann E., 2015. Combined neutron and X-ray imaging for non-invasive investigations of cultural heritage objects. Physics Procedia, 69, 653-660, http://dx.doi.org/10.1016/j.phpro.2015.07.092.

Mannes D., Hanser C., Krzemnicki M., Harti R.P., Jerjen I. and Lehmann E., 2017. Gemmological investigations on pearls and emeralds using neutron imaging. Physics Procedia, 88, 134-139, http://dx.doi.org/10.1016/j.phpro.2017.06.018.

Okamoto S., Hiraoka E., Tsujii Y. and Furuta J., 1983. Neutron radiography of pearls. Journal of the Gemmological Society of Japan, 10(3), 59-65, http://dx.doi.org/10.14915/gsjapan.10.3_59 (in Japanese with English abstract).

Otter L.M., Wehrmeister U., Enzmann F., Wolf M. and Jacob D.E., 2014. A look inside a remarkably large beaded South Sea cultured pearl. Gems \& Gemology, 50(1), 58-62, http://dx.doi.org/10.5741/gems.50.1.58.

Rehren T., Belgya T., Jambon A., Káli G., Kasztovszky Z., Kis Z., Kovács I., Maróti B., Martinón-Torres M., Miniaci G., Pigott V.C., Radivojević M., Rosta L., Szentmiklósi L. and Szőkefalvi-Nagy Z., 2013. 5,000 years old Egyptian iron beads made from hammered meteoritic iron. Journal of Archaeological Science, 40(12), 4785-4792, http:// dx.doi.org/10.1016/j.jas.2013.06.002.

Revol V., Hanser C. and Krzemnicki M., 2016. Characterization of pearls by X-ray phase contrast imaging with a grating interferometer. Case Studies in Nondestructive Testing and Evaluation, 6, 1-7, http://dx.doi.org/10.1016/j.csndt.2016.06.001.

Saprykina I.A., Khokhlov A.N., Kichanov S.E. and Kozlenko D.P., 2017. Old Russian jewelries studies by means of neutron imaging method. 3D Imaging in Cultural Heritage, British Museum, London, 9-10 November, 37-38.

Scarratt K., Moses T.M. and Akamatsu S., 2000. Characteristics of nuclei in Chinese freshwater cultured pearls. Gems \& Gemology, 36(2), 98-109, http://dx.doi.org/10.5741/gems.36.2.98.

Strack E., 2006. Pearls. Rühle-Diebener-Verlag, Stuttgart, Germany, 696 pp.

Sturman N., 2009. The Microradiographic Structures of Non-bead Cultured Pearls. Gemological Institute of America, Bangkok, Thailand, 20 August, 23 pp., www.gia.edu/gia-news-research-NR112009. 
Vitucci G., Minniti T., Di Martino D., Musa M., Gori L., Micieli D., Kockelmann W., Watanabe K., Tremsin A.S. and Gorini G., 2018. Energy-resolved neutron tomography of an unconventional cultured pearl at a pulsed spallation source using a microchannel plate camera. Microchemical Journal, 137, 473-479, http://dx.doi.org/10.1016/j.microc.2017.12.002.

Vontobel P. and Lehmann E., 2010. Results of tomography investigation of small samples at NEUTRA: Options for further improvements. Scientific and Technical Report 2000-Volume VI: Large Research Facilities. Paul Scherrer Institute, Villigen, Switzerland, 68.

Wehrmeister U., Goetz H., Jacob D.E., Soldati A., Xu W., Duschner H. and Hofmeister W., 2008. Visualization of the internal structures of cultured pearls by computerized X-ray microtomography. Journal of Gemmology, 31 (1), 15-21, http://dx.doi. org/10.15506/JoG.2008.31.1.15.
The Authors

\section{Carina S. Hanser}

Albert Ludwig University of Freiburg, Institute of Earth and Environmental Sciences, Albertstrasse 23b, Freiburg im Breisgau, Germany

\section{Dr Michael S. Krzemnicki FGA}

Swiss Gemmological Institute SSEF, Aeschengraben 26, 4051 Basel, Switzerland Email: michael.krzemnicki@ssef.ch

Dr Christian Grünzweig, Ralph P. Harti, Dr Benedikt Betz and Dr David Mannes Laboratory for Neutron Scattering and Imaging, Paul Scherrer Institut, CH-5232 Villigen, Switzerland

\section{Acknowledgements}

The authors thank the following for donating or loaning natural or cultured pearl samples for this research study: Sue Hendrickson (Chicago, Illinois, USA), Dr Wolf Bialoncyk (Vienna, Austria), Michael Bracher (Paspaley, Sydney, Australia), Andy Mueller (Hinata Trading, Kobe, Japan), Prof. Dr Henry A. Hänni (GemExpert, Basel, Switzerland), Isam Alezy (Natural Pacific Pearls, Sydney, Australia), Abdullah Al Suwaidi and Daiji Imura (RAK Pearls, Ras Al Khaimah, United Arab Emirates) and Patrick Flückiger (SwissPearls, Geneva, Switzerland). We also thank Judith Braun and Gina Brombach of SSEF Analytics for their valuable assistance.

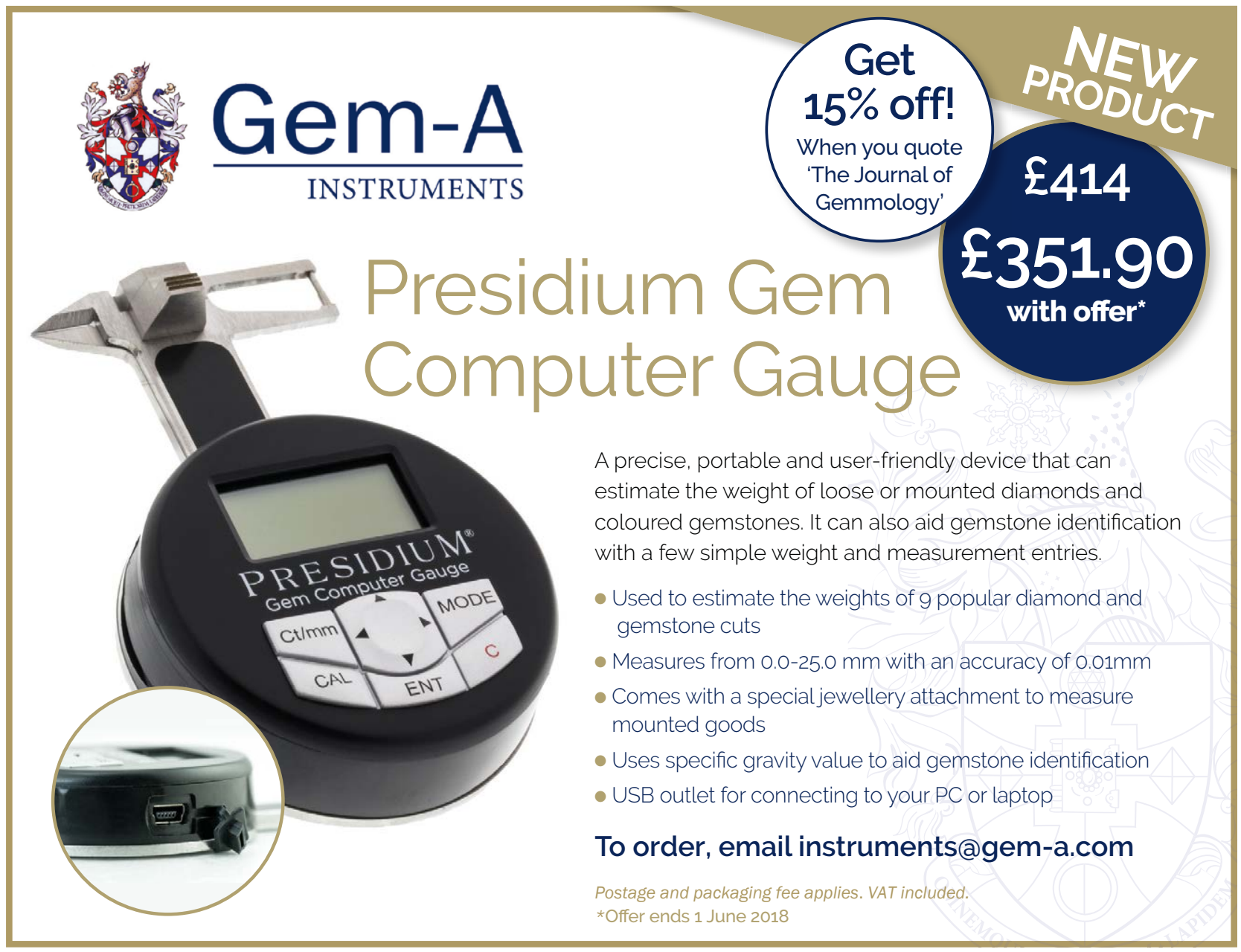

